\title{
RITOS MACABROS A ORILLAS DEL MAR
}

Dos antropólogos, Alberto medina y Francisco Reyes, estudiaron con precisión científica, todos los aspectos que rodearon el sacrificio de un niño de 6 años, por los mapuches de Cautín, para calmar las furias de la Naturaleza, que se desataron a partir del 21 de mayo. Estaban en Puerto Saavedra cuando surgieron las noticias sobre estos macabros ritos que habían tenido lugar a orillas del mar. Fueron los primeros en interrogar a los detenidos acusados de homicidio, según la legislación penal chilena, que no se compadece con las creencias mapuches.

Como resultado de sus investigaciones preparan un estudio completo, más de 100 páginas en el que explican los detalles de esta ceremonia, a la luz del estado económico-social y cultural en que viven ciertas comunidades indígenas. Este estudio, que parece leyenda, tiene un protagonista: José

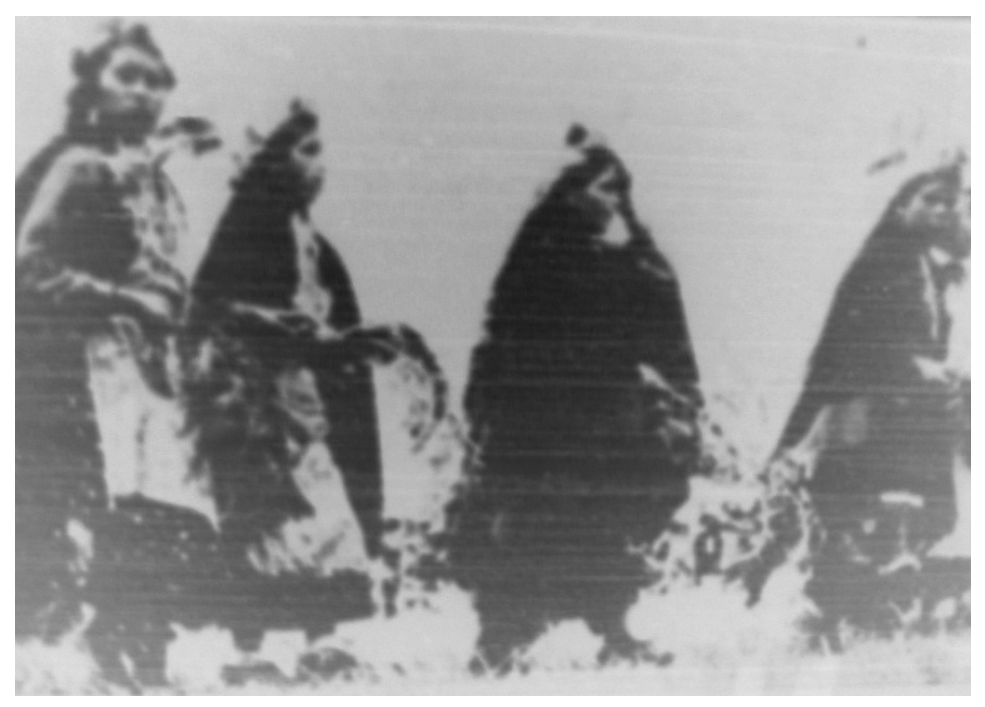

Painecur Painecur, de 6 años, quien fue muerto y trozado "para satisfacer al mar que reclamaba sangre".

Aún cuando en un comienzo, mucha gente se mostró renuente para creer tal noticia, ella fue plenamente confirmada por el trabajo de estos investigadores, pertenecientes al Centro de Estudios Antropológicos de la U. de Chile. No es fácil aceptar que, a breve distancia de Santiago y en plena era atómica, existan chilenos que vivan tan al margen del progreso y la cultura.

ERCILLA conversó con los antropólogos Medina y Reyes y tuvo acceso a los documentos históricos y científicos recogidos por ellos mismos y en los cuales basan sus conclusiones.

He aquí una síntesis de la extraordinaria experiencia que vivieron estos científicos. 


\section{PREDICCIÓN CUMPLIDA}

El 17 de junio, Medina y Reyes se encontraban en puerto Saavedra siguiendo las huellas de los destrozos causados por el sismo. Andaban en un jeep acompañados por el entomólogo Luis Peña. Reyes había salido un momento del lugar donde estaban acampados. Cuando regresó, su compañero Medina lo recibió con una noticia que lo paralizó.

-¡Acertamos! Los mapuches de Collileufú sacrificaron a un niño. Se cumplió lo que anunciamos.

En efecto, en estos días en que tantas predicciones se han desvanecido, hubo una que hizo una dramática confirmación. Fue la de los antropólogos Medina y Reyes, quienes desde diciembre a enero del año pasado, bajo la dirección del profesor norteamericano Emilio Williams de la universidad de Vanderbilt, recorrieron la región ocupada por las reducciones indígenas, realizan un muestreo preliminar que sirviera de base a una investigación completa sobre la situación en que viven los mapuches. En una exposición que hicieron en el seno del Centro de Estudios Antropológicos, anunciaron que, si se produjeran acontecimientos naturales extraordinarios, aflorarían vigorosamente las creencias indígenas que laten en todo mapuche. Una de estas creencias anunciadas fue el sacrificio humano.

En la geografía sureña, los antropólogos señalaron el lugar preciso donde tendrían que ocurrir estos sacrificios. Fue la zona de la costa, en la provincia de Cautín, precisamente, la que fue el macabro escenario de la muerte de José Painecur Painecur. ¿Por qué esa zona y no otra? Porque es la más pobre, la más atrasada y por lo tanto, la que menos se ha asomado a la civilización.

Reyes dice:

-Ahí, a orillas del río Budi, los indígenas viven como recolectores primitivos. Recogen cochayuyo, algunos mariscos, pescan un poco y apenas labran la tierra. No comen pan, porque no lo conocen.

En el análisis realizado por estos antropólogos, las comunidades indígenas de Cautín fueron divididas en tres zonas de acuerdo con sus grados de desarrollo; la de la costa (ahí está Collileufú), la del río Toltén y proximidades de Temuco y la de la Cordillera. Estiman que en esta provincia (la que posee una mayor concentración de indígenas), la población mapuche fluctúa entre 150 a 180 mil, repartidos en comunidades de 80 a 200 miembros cada una. En total, los mapuches alcanzan a 280 mil en todo Chile. 


\section{LA DENUNCIA}

Inmediatamente de conocer las primeras noticias, los antropólogos montaron en su jeep y corrieron aceleradamente al encuentro de los indígenas que habían detenido los carabineros de Puerto Saavedra. Eran tres: dos hombres y una mujer.

Los participantes en la ceremonia fueron 5 , pero con los tres detenidos, la policía pudo desenredar la extraña madeja de supersticiones que había terminado con la vida de un menor. Los detenidos eran: Juan José Painecur (45 años), abuelo del niño sacrificado; Marcos Cuminao Currinca (42 años), quién ofició de "guardián" de la ceremonia, y María Luisa Namuncura Aiñiel (43 años), la "machi" de la comunidad.

También venía la mujer de Painecur, pero en calidad de acompañante, no de detenida.

La denunciante del "delito" fue Rosa Pailacur Antoniancao (25 a 28 años), madre del menor, quien trabajaba como empleada doméstica en Concepción. Contó a los carabineros que tres días después del cataclismo, obtuvo permiso de sus patrones para viajar a la comunidad a visitar a sus parientes, especialmente a su hijo José. No lo encontró. Su padre, Juana José Painecur, mostraba un nerviosismo tan extraño, que inmediatamente le hizo entrar en sospechas. Lo conminó a que le dijera la verdad, y, entonces, él le confesó que su hijo había sido sacrificado para calmar a los dioses.

Rosa Pailacur fue donde los carabineros de Puerto Saavedra y formuló su denuncia, indicando los nombres de algunas de las personas que habían participado en la muerte de su hijo.

\section{EL SACRIFICIO}

Los antropólogos Francisco Reyes y Alberto Medina obtuvieron autorización de los carabineros para interrogar a los detenidos, dos de los cuales (los hombres) se encontraban amarrados a un poste, en un barracón de 8 por 3 metros, que reemplazó a la destruida cárcel. El interrogatorio no fue directo, como los policiales, sino que se practicó soslayando la cuestión fundamental, que era el sacrificio del niño. Los antropólogos, antes que nada, se preocuparon por convencer a los detenidos de que no eran policías, sino estudiosos de los problemas de los indígenas y que tenían la intención de colaborar con ellos. Sólo así consiguieron que los detenidos declararan la verdad. Como intérprete se recurrió a un carabinero mapuche, quien fue la única persona extraña a los científicos y detenidos. 
Francisco Reyes se dirigió a Marcos Cuminao Currinca, el "guardián". Le preguntó si recordaba alguna leyenda mapuche que hablara de sacrificios humanos. Marcos dijo:

-La leyenda dice que cuando hay grandes desastres, es necesario sacrificar una niñita blanca y rubia para calmar a los espíritus.

Reyes aclaró a ERCILLA:

-La en que dijo "blanca y rubia" me indicó que no se refería concretamente a una persona de raza blanca, sino a un niño albino. Su versión fue tan clara y completa, que inmediatamente nos dimos cuenta de que se refería a un hecho muy reciente.

Mientras los científicos hablaban con el "guardián", la "machi" María Luisa Namuncura Aiñiel, murmuraba unas frases con monótona letanía. Estaba sentada al lado de la esposa de Juan José Painecur. Reyes, entonces, se dirigió a la "machi". La saludó, pero ella siguió en su extraña melopea, siempre repitiendo lo mismo.

Francisco Reyes le preguntó directamente qué podía decirle acerca de ceremonias sobre sacrificios humanos. La "machi" continuó en su letanía, que fue traducida por el intérprete de esta manera:

-La sangre de los animales es la que calma a los espíritus.

Después de un momento, la "machi" contó que había tenido visiones que le exigían sacrificios humanos, "como en los antiguos tiempos, y esto lo saben todos los miembros de la comunidad".

En verdad, los hombres más viejos de la comunidad, fueron consultados sobre la visión de la "machi", y estuvieron acordes en estimar la urgencia de un sacrificio humano para calmar a los espíritus que aparecían tan furiosos.

Según los científicos, la "machi" no mostraba afectación ni exaltación. Lo único que la preocupaba era continuar predicando la necesidad de sacrificar a un niño para contentar a los dioses. Miraba hacia los rincones. Jamás dirigió la vista ni a los antropólogos ni al intérprete. Alberto Medina explica:

-La "machi" tenía miedo de que la "ojeáramos". Por eso no nos miraba a la cara. Temía al "mal de ojo" que, por lo demás, es una superstición muy arraigada en nuestro pueblo.

El tercer turno le correspondió al abuelo, Juan José Painecur, quien era el único que mostraba signos de congoja y el único, también, que habló en castellano. Dijo:

-Yo quería mucho a mi nieto. Era mi nieto más querido. ¿Cómo no lo iba a querer, si él me cuidaba el ganado...?

(...) 


\section{EL MÁS DESAMPARADO}

¿Por qué fue elegido este niño? Según los antropólogos, porque era el más desamparado de la comunidad. No tenía a nadie que lo defendiera, salvo su abuelo.

En un comienzo, la "machi" empezó a reclamar un niño albino. No lo había. Pidió uno rubio: tampoco había. Mientras tanto, seguía temblando, la tierra se abría y el mar parecía que no iba a calmar nunca su enojo. Entonces, la "machi" exigió cualquier niño. Había varios.

Fueron consultados los ancianos de la comunidad. Dieron su aprobación y eligieron al menor más abandonado. El abuelo, que tanto quería a su nieto, no pudo resistir a las presiones de la comunidad ni a las exigencias de sus espíritus. Le ordenaron que dejara a su nieto solo en su choza. El "tuerto" Paignan fue destacado para que lo llevara a orillas del mal.

El niño lloró desesperadamente y pidió en todos los tonos que no lo mataran. Pero nadie lo socorrió. 25 personas se encontraban en torno de su cuerpo, cuando Paignan comenzó a degollarlo. Su sangre fue lanzada hacia los cuatro puntos cardinales. En seguida, su cuerpo fue trozado y ofrendado al mar.

Después, los oficiantes regresaron cantando a la comunidad, seguros de que habían satisfecho a los espíritus, y que la Naturaleza volvería a la normalidad.

\section{LA TRADICIÓN}

Para los científicos, esta escalofriante ceremonia indica claramente que nada ha cambiado entre los indígenas que viven a orillas del Budi. Siguen practicando los mismos ritos que sus seculares antecesores. Todas las culturas andinas presentan al sacrificio humano como un denominador común. Cuando Hernán Cortés desembarco en México (siglo XVI) supo que, un año antes, los aztecas habían sacrificado a miles de niños como ofrenda a sus dioses. Alrededor de 1520, los incas realizaron estas mismas ceremonias en Quilaco, pueblito vecino a Concepción. Y en la Biblia misma se relatan episodios semejantes, como el holocausto de Isaac a manos de su padre, Abraham, que no alcanzó a realizarse por la oportuna intervención de la divinidad.

En Chile, la tradición se mantiene incólume y la historia vuelve a repetirse a cada paso. El actual fenómeno del Riñihue, es la reedición del ocurrido en 1575, en el mismo lago, con derrumbes semejantes y con desastrosos efectos. El padre Rosales, a comienzos del siglo XVII, cuenta que: 
- ... para aplacar el enojo del mar y de Caical -señor del mar- pidió que sacrificasen a uno de sus hijos, descuartizándolo en cuatro partes, las echasen al mar para que las comiesen el rey de los peces y las sirenas y se serenase el mal.

Lo mismo relataron José Toribio Medina y el dominico Alfonso Fernández. Por su parte, el ex director del Liceo de Temuco, Tomás Guevara en "Relato de un mito", dice que un indígena le contó:

-Era joven yo todavía. En ese tiempo vino un terremoto. Cuatro adivinos anunciaron un temblor a los caciques y dijeron después: "De una laguna va a salir un Caical, se va a juntar con el Llullul (animal marino fabuloso, con cuerpo de gato y larga cola). Entonces, los caciques hicieron un "guillatún", a orillas de la laguna, en Puancó, por donde iba a salir el Caical, mataron muchas ovejas negras y a un mapuche llamado Antío.

\section{EL SOL}

Según Alberto Medina, Tomás Guevara no entendió claramente a este mapuche. Porque el indígena sacrificado no se llamaba "Antío", sino "Anti", que quiere decir "sol". Cuando ocurrieron cataclismos, como salidas de mar, los indígenas huyeron hacia los cerros y ahí se les hizo necesario complacer al Sol, que les pedía sacrificios humanos. Entonces mataron a todos los de apellido Antilef.

En Puerto Saavedra, Medina y Reyes conversaron con un mapuche muy anciano (su nombre se lo reservaron), quien recuerda claramente los relatos que le hiciera su madre, la que, a su vez, los escuchó de su propia progenitora, que vivió 150 años. Este relato dice:

-...cuando vieron (los mapuches) la salida del mar, subieron a los cerros Trentrén (Secos). Entonces comprendieron que era preciso sacrificar todo lo que se llamara "sol" (anti), para que el Sol secara la tierra e hiciera regresar al mar.

Y todos los Antilef fueron sacrificados.

La fuerza de las supersticiones no sólo brota en esta parte del territorio chileno, sino que se expresa a lo largo de toda América. Los jíbaros, culbas, motilones, conservan su tradición intacta. Y el miércoles pasado, 500 trabajadores, que sacaban guanos en unas islas cercanas a Lima, se negaron a seguir trabajando, porque no valía la pena sacrificarse más, puesto que el 15 de este mes (mañana) el mundo se acabaría, según lo anunciara el pediatra milanés Elio Bianca, conocido como el "Hermano Emman", quien se dirigió acompañado de 90 seguidores al Monte Blanco, a recibir los mensajes del Más Allá, pero encontró las comunicaciones interrumpidas. 


\section{LAS "MACHIS"}

La "machi" es un personaje fundamental en estas ceremonias llamadas "guillatunes". Sobre ella, Alberto Medina dice:

"La 'machi' se siente elegida por seres superiores y se desempeña como mediadora entre lo sobrenatural y su comunidad. Practica su oficio después de recibir el llamado de sus dioses y de completar su preparación bajo la tutela de otras 'machi'. Generalmente, los iniciados en estas prácticas poseen una constitución psicológica exaltada y aprenden ceremonias, danzas rituales, toque de instrumentos, preparación de brebajes, uso de sortilegios y la manera de comunicarse con los espíritus. Sus instrumentos principales son: el tambor, el arco de hierro, del que penden cascabeles de plata; una especie de atraca, y el símbolo que siempre se ubica frente a la puerta de su casa, llamado 'rehue', que consiste en un tronco de maqui labrado en forma de escalera y que termina en una cabeza humana tallada. Una vez terminado su aprendizaje, la novicia es consagrada después de una fiesta muy complicada, en que cae en éxtasis y mezcla su sangre, por diferentes conductos, con la 'machi' consagrante. La ceremonia se completa cuando la novicia sube al 'rehue', bailando y tocando el tambor. Su consagración constituye una fiesta llena de algarabía y todos los miembros de la comunidad se sienten admirados ante la nueva sacerdotisa".

\section{EL "GUILLATÚN"}

Alberto Medina define el "guillatún", que es el acto religioso nacional de los araucanos, de la siguiente manera:

"Es una ceremonia destinada a solicitar de los poderes sobrenaturales beneficios para la comunidad o la terminación de los males que se han desencadenado. Esta es la principal función litúrgica de la 'machi'. Se prepara con cierta anticipación y se pide a los miembros de la comunidad que ofrezcan animales para los sacrificios. Mensajeros recorren las comunidades cercanas y convocan a la fiesta, que se efectúa en una pradera engalanada con ramas de canelo. Cuando llegan los invitados se traen ofrendas, se charla y se baila ininterrumpidamente. El jefe de la ceremonia pronuncia un discurso, explicando los objetivos de ella. Los sacrificios sangrientos se practican después de solicitar del animal que va a ser muerto que sirva de intercesor ante las divinidades. A las 
primeras notas musicales, se le vendan los ojos a la 'machi' y ella, con el tambor y los cascabeles, baila junto a los demás oficiantes, cantando estrofas que los demás corean. Después, a una señal, se practica el holocausto general, en el que cada participante decapita su animal. El jefe de la fiesta, junto con los ancianos, hombres y muchachos, realizan evoluciones sincronizadas. La 'machi' canta una ofrenda en la que plantea los motivos del derramamiento de sangre y esta rogativa generaliza a todos los participantes. Después de otras ceremonias muy estudiadas, la 'machi' se detiene, tiembla, vacila y cae. Los pajes que la han acompañado la sostienen y aparentan luchar contra los demonios. La ceremonia sube de tono. El jefe de la fiesta hace signos misteriosos y la 'machi', con ciertos gestos, obliga a enmudecer a los participantes, quienes saben que llega la hora en que ella les comunique que los dioses han mirado con buenos ojos la fiesta y han recibido las súplicas".

\section{CONCLUSIONES}

Francisco Reyes sintetizó para ERCILLA las conclusiones a que han arribado después de estudiar los detalles del "guillatún" a orillas del Budi. He aquí sus declaraciones:

-Para examinar en su justa medida e importancia el hecho ocurrido debemos indagar todos los aspectos de la vida comunitaria de los araucanos, junto a sus tradiciones y cultura. Ellos poseen una organización social que viene desde mucho antes de la llegada de los españoles. Ha sufrido alteraciones y cambios, pero siempre mantienen fuertes raíces en el pasado y conservan significación dentro del grupo comunitario. Para explicarnos lo ocurrido hay que examinar los valores que permanecen intactos o latentes dentro de la comunidad y que son consecuentes con sus prácticas. Los araucanos, a quienes podemos considerar dentro del concepto de "minoría", tienen una organización social y actitudes de comportamiento para desenvolverse en su vida diaria, creen en ciertos poderes mágicos y humanos, respetan determinadas normas de conducta y dan a cada miembro un papel y un status dentro de la comunidad. Establecen sanciones para ciertos actos, exaltan determinadas cualidades y juzgan nuestro comportamiento como diferente al de ellos. De este modo, tienen valores distintos para su vida, estiman como primordial lo "sobrenatural" y les dan una alta jerarquía a los "machis", que son los administradores de lo "sobrenatural". De aquí proviene la importancia de los "machis" para orientar las actitudes y el pensamiento de la comunidad cuando ocurren acontecimientos extraordinarios o graves desastres que necesitan una explicación o un punto de apoyo frente a la incertidumbre. 
-Para el antropólogo familiarizado con diversas actitudes y en especial con pueblos distintos a nuestra cultura no es difícil descubrir el funcionamiento y los valores peculiares de un determinado grupo. Y en toda sociedad está presente la ley, la ley del grupo. La forma en que ellos explican sus vidas y objetivos y los acontecimientos de la naturaleza no pueden ser analizados según nuestro criterio científico, psicológico y técnico. Ellos poseen otra ciencia y otra técnica, las que consideran totalmente útiles para sus fines.

Ritos macabros a orillas del mar. Revista Ercilla,16-18, 12 de julio de 1960. 